\title{
Cultural Influences in Probabilistic Thinking
}

\author{
Sashi Sharma ${ }^{1}$ \\ ${ }^{1}$ Department of Mathematics, Science and Technology Education, The University of Waikato, Hamilton, New \\ Zealand \\ Correspondence: Sashi Sharma, Department of Mathematics, Science and Technology Education, The University \\ of Waikato, Hamilton, New Zealand. Tel: 61-7838-4500 Ext. 6298. E-mail: sashi@ waikato.Ac.nz \\ Received: May 27, 2012 Accepted: August 8, 2012 Online Published: September 24, 2012 \\ doi:10.5539/jmr.v4n5p63 URL: http://dx.doi.org/10.5539/jmr.v4n5p63

\begin{abstract}
Concerns about students' difficulties in statistics and probability and a lack of research in this area outside of western countries led to a case study which explored form five (14 to 16 year olds) students' ideas in this area. The study focussed on probability, descriptive statistics and graphical representations. This paper presents and discusses the ways in which students made sense of probability constructs (equally likely and proportional reasoning) obtained from the individual interviews. The findings were interpreted in relation to cultural perspective. The findings revealed that many of the students used strategies based on cultural experiences (beliefs, everyday and school experiences) and intuitive strategies. While the results of the study confirm a number of findings of other researchers, the findings go beyond those discussed in the literature. The use of beliefs, everyday and school experiences was considerably more common than that discussed in literature. The paper concludes by suggesting some implications for teachers and researchers.
\end{abstract}

Keywords: probabilistic thinking, culture, equally likely, independence, proportional reasoning, high school students, implications for practice

\section{Introduction}

... the learning of probability is essential to help prepare students for life, since random events and chance phenomena permeate our lives and environment (Gal, 2005, p. 40).

The above quote by Ido Gal reminds us that probability is part of our everyday life. It influences how we make individual and collective decisions in everyday activities. For example, many games of chance are ruled by the roll of dice, toss of a coin or random numbers that computer games use. There are also the weekly lottos and "Big Wednesday Draws". Many other areas of our lives are increasingly being described in probabilistic terms. We hear that a court case has been decided beyond "reasonable doubt". "Doctors say that that they are $95 \%$ confident that a new medicine is effective". Decisions concerning risk and opinion polling are made using an understanding of probabilistic reasoning. As Pratt (2005, p. 171) writes:

Indeed it seems probability is one of the few areas of mathematics that informs explicitly the way in which we conduct our everyday lives.

According to (Gal, 2002), people need to statistically and critically evaluate examples such as above and where appropriate communicate their opinions to others verbally and in writing. Moreover, Gal claims that anyone who lacks these skills is functionally illiterate as a productive worker, an informed consumer or a responsible citizen. However, people without probability knowledge may be misled or have difficulty in interpreting and critically evaluating such information. Best (2001) claims that consumers need to understand that statistics is a social construct and that people debating social problems may choose statistics selectively and present them to support their point of view. He notes that people often choose to rely on an author's interpretation rather than engage adequately with such information.

The importance of probability in everyday life have led to calls for an increased attention to this strand in the mathematics curriculum (Jones et al., 2007; Ministry of Education, 2007; Pratt, 2005; Schield, 2010). For example, Schield argues that one of the most important goals for teaching statistics in schools should be to prepare students to deal with the statistical information that increasingly impacts on their lives and environments. According to Gal (2005) attention to real-world demands should be part of the consideration that guide what gets taught, assessed 
and valued in the statistics classroom.

Greer and Mukhopaday (2005) assert that probability is a tool that helps quantify uncertainty. They claim that real life data is variable and probability helps us describe and quantify how things vary. As a result probability is not something that helps us to gamble or play games of chance, it helps to investigate the real world we live in and respond critically to claims made by others. The authors add that probability has been usually taught as part of the statistics strand and is often considered as the harder and less relevant topic. However, probability is an important learning area in its own right and should be learned for its sake. In recognition of the importance of probability in both school and out of school settings, there has been a movement in many countries to include probability at every level in the mathematics curricula. In western countries such as New Zealand (Ministry of Education, 2007) these developments are reflected in official documents and in materials produced for teachers. Statistics is one of the three strands in the new curriculum document and seen as critical in the learning of mathematics. The use of meaningful contexts and drawing on students' experiences and understandings is recommended for enhancing the students' understanding of probability (Ministry of Education, 2007; Watson, 2006). Paralleling these moves, Fiji has also produced a new mathematics prescription at the primary level that gives more emphasis to statistics at this level (Fijian Ministry of Education, 1994) although probability is first introduced in the early years at the secondary level.

From the above ideas it can be argued that informal probability is firmly established in common culture. Formal probability is mostly introduced in the early years as a model of chance in the context of random events which we hope students see as random. As such there is a potential for conflict and interactions between the knowledge of chance and probability which students acquire informally and mainly outside school and formal knowledge that schools present (Amir \& Willuams, 1999). Indeed we may be building the model of probability on a weak foundation.

Jones et al. (2007) raised concerns about the lack of research in probability education outside of western countries. The researchers advocated large and small scale studies that examined group and cultural differences on students' thinking in decision making and probability estimation tasks. While some research (Chiesi \& Primi, 2009; Peard, 1995; Polaki, 2002) has been undertaken outside of western countries, these studies relate strongly to American or English research and do not focus on how the culture of the subjects may have impacted on their decision making (Greer \& Mukhopadhyay, 2005).

The aim of this paper is to examine the influence of culture in probabilistic thinking. Specifically, it discusses findings from a case study which explored statistical ideas of high school students in Fiji (Sharma, 1997). The paper is organised in five sections. First of all, it attempts to define culture and review literature on aspects of culture in mathematics education. Second, it briefly explains research in probability education. After providing a brief overview of Sharma study, the paper discusses the results and interprets the findings. In the final section, some suggestions for teaching and learning and research are considered.

\section{Culture and Mathematics Education}

Historically the emergence of probability from games of chance (Batanero, Henry, \& Parzysz, 2005; Bishop, 1988; Gabriel, 1996) makes it clear how probabilistic thinking is culturally embedded. Gabriel discussed the complex relationship between gambling and spirituality among indigenous American people. Indeed this cultural knowledge is important when teaching students from this community. However, there appears to be minimal literature that deals with the educational implications of the cultural perspective in statistics education (Shaughnessy, 1992; 2007). This is surprising because statistics educators can lead the way in this regard. Rossman, Chance and Medina (2006) and Scheaffer (2006) claim that whereas mathematics educators often regard context as an obstacle that can obscure the abstract mathematical ideas at the core of the problem, statistics educators usually recognise that their world is indeed embedded in context. They state that students need multiple opportunities to relate their comments to the context when drawing conclusions. Perhaps it is easy for statistics educators to embrace the importance of culture although it does not mean that culture is less important for mathematics education. This section draws on relevant literature from mathematics education research to explore these issues in depth.

There are several obstacles facing any researcher who wishes to examine issues in statistics education through a cultural lens (see Bishop, 1988; Lubienski, 2000). Additionally, culture is situated at the intersection of several areas of inquiry including those involving race, power and social class (Presmeg, 2007). This complexity may pose major challenges for researchers working in this area. First, because of the specialised nature of academic fields, statistics education researchers might not be familiar with emerging research and perspectives relating to culture 
and power. According to Lubienski (2000) researchers wishing to conduct cultural studies of statistics classrooms need to be grounded not only in statistics education research but also in research from fields such as linguistics, anthropology and sociology. This may be particularly difficult because the perspectives guiding studies of culture in these fields have been both highly debated and shifting (Bishop, 1988; Nasir et al., 2008; Vithal \& Skovsmose, 1997; Wax, 1993; Zaslavsky, 1998). Scholars have even promoted cultural difference model in which the language and practices of all students need to be considered in the classroom.

Secondly, mathematics and statistics curricula have been slow to change due primarily to a popular and widespread belief that mathematics is culture free knowledge (Benn \& Burton, 1996; Bishop, 1988). The argument is that the probability of rolling a six on a fair die is one-sixth wherever you are. However, as Bishop points out as soon as one begins to focus on the context of this statement ones beliefs in universality of mathematics tends to feel challenged. Additionally, people think about probability in different ways and these views can be manifested in their thought processes.

In the last decade, the field of research into the role of culture in mathematics education has evolved from ethnomathematics, critical mathematics education and everyday mathematics although these perspectives are connected (Bishop, 1988; Nasir et al., 2008; Vithal \& Skovsmose, 1997). Ethnomathematics is the study of cultural aspects of mathematics (D’Ambrosio, 2001). It encompasses a broad cluster of identifiable groups, ideas ranging from distinct numerical and mathematical systems to multicultural mathematics education (Zaslavsky, 1998). From these perspectives, an attempt has been made to develop an alternative mathematics education or culturally responsive pedagogy which expresses social awareness and political responsibility (Averill et al., 2009; Martin, 2006; Vithal \& Skovsmose, 1997).

It must be acknowledged that the notion of culture has been contested and given varied and sometimes competing definitions and interpretations in the literature (Nasir et al., 2008; Vithal \& Skovsmose, 1997; Zaslavsky, 1998). Bishop (1988, p. 5) favoured the following definition of culture:

Culture consists of a complexity of shared understandings which serves as a medium through which individual human minds interact in communication with one another.

Presmeg (2007) stated that while the above definition highlights the communicative function of culture that is particularly relevant in teaching and learning mathematics, it does not focus on the dynamic view of culture that results in cultural change over time due to movement between different social groups. Presmeg viewed culture as an all-encompassing umbrella construct that enters into all the activities of humans in their communicative and social enterprise (2007, p. 437). Presmeg adds that researchers may speak of the culture of a society, of a school and culture in all these levels of scale can impact on the mathematical learning of students. According to Presmeg, the mathematics classroom itself is one place in which culture is contested, negotiated and manifested.

This paper draws on a perspective of culture with roots in Vygotskian theory of learning (Vygotsky, 1978). In this perspective, culture can be described as a group of people's shared way of living. It is used to encompass commonly experienced aspects of the groups lives such as shared knowledge, backgrounds, values, beliefs, forms of expression and behaviours that may impact classroom interactions (Nickson, 1992). This means that the cultural practices that we engage in as we move across everyday, school and professional contexts both shape and constitute our learning. However, this can become a complicated concept in schools in which school and classroom cultures exist within broader cultural contexts. Students' home and school cultures may be very different from one another which means students need to operate differently in these contexts while for other students these cultures may be more compatible (Abbas, 2002; Averill et al., 2009; Bourdieu, 1984; Clark, 2001).

The above definition resonates with principles of socio-cultural theories combined with elements of constructivist theory which provide a useful model of how students learn mathematics. Constructivist theory in its various forms, is based on a generally agreed principle that learners actively construct ways of knowing as they strive to reconcile present experiences with already existing knowledge (Barker, 2001; Confrey \& Kazak, 2006; von Glasersfeld, 1993). Students are no longer viewed as passive absorbers of mathematical knowledge conveyed by adults; rather they are considered to construct their own meanings actively by reformulating the new information or restructuring their prior knowledge through reflection (Cobb, 1994). This active construction process may result in misconceptions and alternative views as well as the students learning the concepts intended by the teacher.

Another notion of socio-cultural theory derives its origins from the work of socio-cultural theorists such as Vygotsky (1978) and Lave (1991) who suggest that learning should be thought of more as the product of a social process and less as an individual activity. In this perspective learning is viewed as developing greater participation in both 
in-school and out-of-school contexts. There is strong emphasis on social interactions, language, experience, collaborative learning environments, catering for cultural diversity, and contexts for learning in the learning process rather than cognitive ability only.

Indeed a significant issue for mathematics education is the dilemma of how to investigate and incorporate cultural (out-of-school) mathematics in school mathematics classrooms in ways that are meaningful to students and that do not trivialise the mathematical ideas inherent in cultural practices. Nasir et al. (2008) as part of a study on thinking and learning across contexts, asked college students to solve average problems in two ways. In one set of tasks, the problems were framed by basketball practices and the other were given in the format of a typical school mathematics worksheet. The researchers report that some of the subjects demonstrated rich mathematical problem solving strategies in non-school context in a form markedly different from what we typically consider school knowledge. These findings led these researchers to reject the notion that knowledge as independent and hence transportable, it is dependent on context. Similar suggestions have been made by Gal (2004). Gal refers to two main type of contexts (situations in which data is interpreted), enquiry and reader. In enquiry contexts people act as data producers (eg statisticians and researchers) and usually interpret their own data whereas reader contexts emerge in everyday life situations such as watching television or reading newspapers and require people to evaluate someone else's others. He questioned the assumption that students who learn to process data (school settings) can transfer these skills to interpreting and critically evaluating statistical information (everyday situations). For Gal, statistical knowledge is contingent upon the context or setting. This view led Gal (2004) to develop a dynamic model of statistical literacy which focuses not only on cognitive skills including critical thinking but also on the dispositional aspects such as beliefs, values and attitudes. However, Gal does not refer to cultural knowledge explicitly in his model.

The above body of research on the relationship between cultural knowledge and domain knowledge provides an important lens through which we can understand and study probability classrooms which are sometimes considered culture-free.

\section{Research on Probability}

A number of research studies from different theoretical perspectives show that students tend to have conceptions about probability which impact on their learning. Some prevalent ways of thinking which inhibit the learning of probability are discussed below.

\subsection{Representativeness}

According to this strategy students make decisions about the likelihood of an event based upon how similar the event is to the population from which it is drawn or how similar the event is to the process by which the outcome is generated (Kahneman \& Tversky, 1963). A consequence of beliefs in representativeness lead to the negative and positive recency effects. Students exhibiting the negative recency effect tend to assign a higher probability for flipping a tail on the fifth flip if four heads have occurred in a row. On the other hand, those using the positive recency effect believe that it is more likely to flip a head on the fifth flip due to the belief that the pattern will continue (Shaughnessy, 1992). Chiesi and Primi (2009) investigated recency effects in primary and college students. Results indicated that positive recency effect decreased with age whereas no age related differences were found for the negative recency effect.

\subsection{Equiprobility}

People tend to think that symmetrical objects such as coins and dice always produce outcomes which are equally likely. For example, if one tosses two coins, one is more likely to get the outcome one head and one tail than to get, say, two heads. However, many people assume that all outcomes have an equal chance of occurring (Lecoutre, 1992). Lecoutre also found that the equiprobability bias was highly resistant to change.

Confronting pupils with the total of two dice in a computer based environment, Pratt (2005) also identified responses in accordance with equiprobability. He concluded that students base their decisions in random experiments on different types or internal and external resources. Regarding equiprobability, internal resources such as unpredictability, irregularity and fairness are mainly in play.

\subsection{Proportionality Misconception}

Proportional reasoning is critical to understanding of making predictions in probability situations. Research indicates that students think the bigger the absolute size of something the higher the probability (Shaughnessey, 2007; Watson \& Callingham, 2003). Hence it is more likely to choose a red marble from a bag with 10 red and 20 blue 
ones than choosing one from a bag of 5 red and 10 blue ones. A large spinner is more likely to come with a win than a smaller spinner even when the relative areas are the same.

Green (1991) asked questions where not only the total numbers of balls were different but also the proportions of colours in the containers. For instance, in one task middle school students were asked to compare bags with 12 black and 4 white counters and 20 black and 20 white counters. The specific question was: Which bag would give a better chance of giving a black counter? Green identified four strategies across similarly structured items: choose the bag with more total counters, choose the bag with more black counters, choose the bag with the greater black-white difference and choose the bag with the greater black:white ratio.

\subsection{Beliefs}

Research (Amir \& Williams, 1999; Sharma, 1997; Truran, 1994) show that a number of students think that their results depend on a force, beyond their control, which determines the eventual outcome of an event. Amir and Williams (1999) interviewed thirty-eight 11 to 12-year- old students in their first year of secondary school about their concepts of chance and luck, their beliefs and attributions, and their probabilistic thinking. Some pupils thought God controls everything that happens in the world while others thought God chooses to control, or does not control anything in the world. There were also beliefs directly related to coins and dice; for instance, when throwing a coin tails is luckier.

Zimmermann and Jones (2002) studied high school students' thinking and beliefs by confronting them with problems involving two-dimensional probability simulations. Various student beliefs emerged from their analysis of the data. They categorised these into helpful or problematic beliefs. What they found was disturbing was the fact that some students believed, albeit to different degrees that simulation cannot be used to model a real-world probability problem.

Probability educators should realise that the students they teach are not new slates waiting to have the formal theories of probability written upon them. The students already have their own built-in pre-conceptions, biases and beliefs about probability and these cannot, as it were, be simply wiped away by rolling dice and tossing coins. If student conceptions are to be addressed in the process of teaching, then it is important for teachers of probability to become aware of the alternative conceptions (cultural experiences, beliefs, values) that students bring to classes and teach accordingly.

\section{Overview of Study}

Overall, the Sharma (1997) study was designed to investigate what ideas do form five students have about statistics, and how do they construct these. The secondary school selected for the research was a typical high school. The sample consisted of a class of 29 students aged 14 to 16 years of which 19 were girls and 10 were boys. According to the teacher, none of the students in the sample had received any in - depth teaching on probability prior to the interviews. 14 students participated in the individual interviews. This group of 14 was representative of the larger group in terms of abilities and gender.

\subsection{Tasks}

The instrument consisted of probability and statistics tasks, each with a series of questions. Due to space limitations, data from two probability tasks are reported here. In contrast to traditional pedagogic setups which are limited to closed questions, in all tasks students were provided opportunities to either explain their thinking or express their opinions. The two tasks are described below.

In situations such as tossing a coin (a one-stage experiment), the outcomes are said to be equally likely, the particular one that does occur when a coin is tossed being purely a matter of chance. The theoretical probability can be based on an analysis of the sample space and uses number or simple geometric measures to determine the likelihood. The advertisement regarding the sex of a baby (Item 1) explored students' understanding of the equally likely concept in everyday context.

Item 1: Advertisement involving sex of a baby

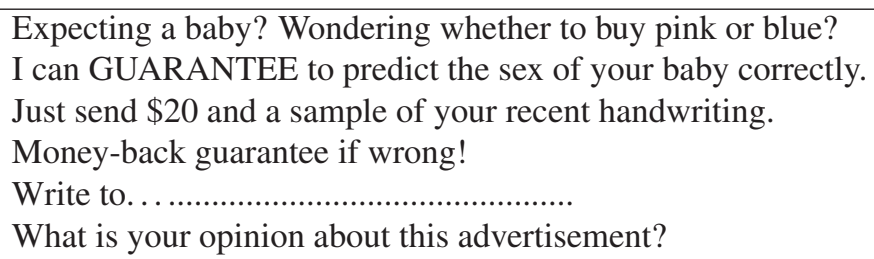


The comparison of probabilities problems, Items 2A and 2B were used to explore students' conceptions of proportional reasoning which is crucial to a conceptual understanding of probability. It is fundamental to making connections between populations and samples drawn from these populations and hence provides a basis for statistical inference.

Item 2A: Black and white marble problem

Meena and Ronit have some marbles. Meena is 10 years old. In her box, there are 10 white
marbles and 20 black ones. Ronit is only 8 years old. In her box there are 20 white marbles and
60 black ones. They play a game. The winner is the child who pulls out a white marble first.
If both take out a white marble at the same time then no one is the winner and the game has to
go on. Ronit claims that Meena has a greater chance of pulling out a white marble because she
is older, and cleverer.
What is your opinion about this?

Item 2B: Red and blue marble problem Box A and Box B are filled with red and blue marbles as follows:

\begin{tabular}{|cc|}
\hline Box A & Box B \\
6 red & 60 red \\
4 blue & 40 blue \\
Each box is shaken. You want to get a blue marble, but you are only allowed to pick one \\
marble without looking. \\
Which box should you choose? Please explain your answer. \\
\hline
\end{tabular}

\subsection{Interviews}

Each student was interviewed individually by the researcher in a room away from the rest of the class. The interviews were tape recorded for analysis. Each interview lasted about 40 to 50 minutes. Paper, pencil and a calculator were provided for the student if he or she needed it. The students were told that the purpose of the interview was to find out what they knew about probability, it was not a test.

\subsection{Analysis of Data}

Analysis of the interview responses indicated that the students used a variety of strategies for solving the probability problems. The data also revealed that many of the students held beliefs and used strategies based on prior knowledge which, would turn to inhibit their development of formal probability ideas. Informed by research (Tarr \& Jones, 1997; Watson \& Callingham, 2003), the researcher created a simple four stage-based rubric that could be helpful for describing research results relating to students' probabilistic conceptions, planning instruction in probability and dissemination of findings to mathematics educators. The four categories in the rubric are: non response, non-statistical, partial-statistical and statistical. These are described in Table 1. 
Table 1. Characteristics of the four categories of responses

\begin{tabular}{ll}
\hline Response Type & Descriptors \\
\hline Non-response & Due to reading or writing difficulty, students are unable to ex- \\
& plain their thinking and often guess answers. With respect to \\
& statistical terminology, students provide random or inappropri- \\
& ate explanations. Complete silence, I don't know, I have forgot- \\
& ten the rule, I just guessed. \\
& Refer to everyday and school experiences or make connections \\
Non-statistical responses & with other learning areas. Problems with language Refer to be- \\
& liefs, luck, superstition, religion Hold the pervasive belief that \\
& they can control outcomes of events. \\
& Adapted the rules or applied them inappropriately. Refer to rep- \\
Partial-statistical responses & resentativeness, proportionality misconception, equiprobability \\
& biases. Could not adequately explain reasoning Refer to out- \\
& come approach Inconsistent reasoning. \\
& Able to justify reasoning by using classical or frequentist inter- \\
pretation Extend rules to unfamiliar situations Uses numerical \\
probabilities to justify reasoning. Listing the sample space.
\end{tabular}

\section{Results and Discussion}

This section reports data on students' understanding of equally likely and proportional reasoning constructs. In this paper the main focus is on the non-statistical responses (in which students made connections with cultural experiences). Extracts from typical individual interviews are used for illustrative purposes. Throughout the discussion, I is used for the interviewer and $S_{n}$ for the $n$th student.

\subsection{Equally Likely Outcomes}

None of the students were considered statistical on Item 1. This could be due to the context of the task or language difficulties. Most of the responses fell in the middle two categories (partial-statistical and non-statistical). The non-statistical category consisted of students' responses which related the data to their beliefs and everyday experiences in non-statistical ways. There was no evidence of students integrating theoretical and experimental views of probability. Strong influences of religious beliefs were apparent when students were asked to comment on the advertisement. Even when challenged about how the people placing the advertisement could make money, the students could not see that roughly half the babies born would be girls and half would be boys. Anyone can expect to be right in half the number of cases just by guessing. Even if predictions are made incorrectly, some will not bother to complain anyway. Even if they did, a clear profit can be made on $50 \%$ of the all the $\$ 20$ payments sent in. The powerful nature of their religious beliefs is reflected in the response of student 17:

As I have told you before that God creates all human beings. He is the one who decides whether a boy is born or a girl is born. Unless and until like now the ...... have made a machine if one is pregnant and they can go there and they tell you whether the baby is a girl or a boy. But they can't tell until the baby is 8 months old. So that it means that the God created like that before we can't tell that the baby is a male or a female.

The three students who referred to previous experience when commenting on the advertisement regarding the sex of the baby, said that the advertisement was placed just to earn money. When asked to explain their thinking, students talked about businesses putting advertisements to sell their products.

\subsection{Proportional Reasoning}

A minority of responses were statistical in nature. Two students in the study showed a firm grasp of the ratio concept on the first task and four on the second. For example, student 2 and student 12 were not only able to say that age did not matter in chance games, but were also able to work out the correct probabilities for Meena and Ronit. Additionally, four students were not only able to say that it did not matter which box with red and blue marbles one should choose but were also able to work out the correct probabilities for the two boxes.

The data showed that in 11 cases, students did not use a statistical model but based their reasoning on their cultural beliefs and experiences. Two common beliefs identified on the proportional reasoning tasks related to causality and outcomes being controlled. Five students tried to seek a cause for an action on Item 2A and three on Item 
2B. The students said that because Meena was older, she had more chance of pulling out a white marble. Others claimed that Ronit had more chance of pulling a white marble because she had more whites in her bag.

A few students missed the point of the question by focussing on whether the game was fair. This is reflected in the comment made by student 26 :

This is not a fair game; for this the game should be played by same aged people and there should be equal number of marbles in the box.

Student 6 used the control strategy for both the questions. For example, for the question involving blue and red marbles, the student offered the following explanation:

Now the marbles are in a box. It depends on what is inside. It depends on hands which one it pulls.

In addition to basing their thinking on beliefs some students based their reasoning on cultural experiences. For the proportional reasoning task about Meena and Ronit having black and white marbles, one student explained why it was fair that Ronit, the younger child, had more marbles.

At my home, I got three brothers so when my father gets two apples, then he gives one whole apple to my smaller brother and us two brothers, we get half each. (Student 25)

Rather than attending to proportionality information given on the marble task, 10 white and 20 black marbles versus 20 white and 60 black marbles, two students based their reasoning on previous sports experience. The following discussion illustrates this misunderstanding:

I: Now Meena says that the game is not fair because in Ronit's box there are more white marbles than in her box. What is your opinion about this?

S20: Eh ... So if you play a game it should be equally in number.

I: What do you mean by equally?

S20: Like soccer; if you are playing there should be 11 players side. Then you will be able to have a win eh. So here it is like marble it is 10 white and 20 black marbles. So the game should be equally.

It is clear that this student, instead of performing adequate proportional calculations, used his prior experience to deal with the task.

\subsection{Probability: A Cultural Context}

The findings discussed in this paper show that often student explanations were not based on probabilistic principles but on students' own readily accessed beliefs and everyday experiences. There were beliefs directly connected with marbles (Item 2). The general belief is that the outcomes can be controlled by the individual.

The findings also show that in a number of cases, students based their reasoning and estimates on their beliefs about the world and cultural events. Four students even employed quite sophisticated belief systems, for example, positive visualisation (if people believe in the beneficial effects of doing something, actually doing so will increase their chances of benefiting from it). The view that an outcome is due to luck or fate is a widespread belief within the Indian community. This was evident with the students interviewed. Three students mentioned luck associated with sighting pigeons when asked to elaborate on luck. These examples reveal the extent to which belief in luck permeates the thinking of Indian students. Thus, it is not surprising that these formed an important component of these students' explanations.

In addition to reasoning on the basis of control and luck, some students based their explanations on their religious beliefs and the causality perspective. The students thought God controls everything that happens in the world. For the advertisement regarding the sex of a baby (Item 1), three students thought that one can not make any predictions because the sex of the baby depends on God. The data showed that a number of students did not use probabilistic reasoning but based their reasoning on the causality assertion. For instance, the common belief identified on the proportional reasoning tasks (Items 2A, 2B) related to causality. When asked to make predictions five students, at least once on the tasks, looked for factors that caused the behaviour or event under consideration. The students said that because Meena was older, she had more chance of pulling out a marble. Others claimed that Ronit had more chance of pulling a white marble because she had more whites in her bag.

The prominence of the causality perspective such as younger one first can be explained in terms of student experiences within the community. In everyday life children learn mainly by observing what their parents and elders do 
and practising or imitating their behaviour themselves. Generally the younger child is given the best of everything. For example, students may observe that parents and grandparents usually serve the younger children first. In the play situation, this is reflected in the older children giving the younger children the first chance. This is particularly evident in games such as snakes and ladders which require children to take turns. Hence, in the particular example (Item 2A), the issue of Meena having more chance of pulling out a white marble because she is older became one of a concern for cultural fairness.

In addition, the results show that everyday reading strategies of skimming and using the context or knowledge of the world to support comprehension are insufficient for reading probabilistic English. The findings indicate that in some cases the meaning intended by the researcher on the interview tasks was not that constructed by the students. As a result, students constructed responses based on these unintended interpretations. Rather than attending to proportionality information given on a marble task, (10 white and 20 black marbles versus 20 white and 60 black marbles) some students based their reasoning on their everyday language skills. Ordinary expectations of the way words are put together in English led students to assume that the phrase at the same time in the question will mean some action. For instance, one student interpreted the problem involving Ronit and Meena as a game involving competition and a winner.

The findings concur with the results of studies by Amir and Williams (1999) and Truran (1994). However, this may be problematic if students' prior experiences and beliefs conflict with the probability concepts that teachers are trying to teach them. For instance, if students believe that outcomes can be controlled by individuals or by some outside force then they need help to overcome a reluctance to predict using sample space

In spite of the importance of relating classroom mathematics to the real world, the findings in this section indicate that students frequently fail to connect the mathematics they learn at school with situations in which it is needed. For instance, while students could estimate theoretical probability for rolling a die, they had difficulty estimating probabilities for a real life situation (Item 1). In fact none of the students used theoretical or experimental interpretations for this problem. Clearly, the results support claims made by Gal (2004), Nasir et al. (2008) and Groth (2007) that learning for students is situation specific and that that connecting students' everyday contexts to academic mathematics is not easy.

Overall, the findings provide evidence of Bishop (1988)s assumption that formal mathematics education may produce cultural conflicts between students' everyday culture and the culture of mathematics. Indeed probability has some cultural aspects which can be differentiated in divergent everyday experiences and beliefs. The ideas discussed in this section have implications for teaching and research.

\section{Implication for Teachers and Research}

The results obtained indicate that a majority of students did not have a clear idea of the probability constructs discussed in this paper. It must be acknowledged that the open-ended nature of the tasks and the lack of guidance given to students regarding what was required of them certainly influenced how students explained their understanding. The students may not have been particularly interested in these types of questions as they are not used to having to describe their reasoning in the classroom. Some students in this sample clearly had difficulty explaining explicitly about their thinking. Despite these limitations, the findings of the study have several implications for teachers and research.

First of all, when beginning instruction on probability, it is important for teachers to know the individual abilities of the students. Once the type of understanding has been explored, it is crucial for teachers to teach accordingly. Teachers can assess their students' understanding through individual interviews. A major disincentive for teachers is the amount of time required to interview each student. To deal with this difficulty, teachers can get an insight into student's learning by interviewing just a couple of students and generalising to the class. Teachers could also use paper and pencil tests where students are asked to explain their thinking.

It seems that probability concepts are counter-intuitive and students may often hold these contradictory interpretations simultaneously. Depending on the nature of the task, this situation often generates inconsistencies in students' responses. Teachers must be aware that the level of understanding demonstrated on one context does not necessarily mean that the same understanding will be used in a different context.

It appears that learning about probability constructs is a complex process and requires more emphasis and explicit planning, teaching and assessment. Furthermore, teachers need to consider integrating both cultural and domain knowledge in the classroom. Such integration will enable students to construct meanings from data and build the 
foundation for an understanding of these ideas.

The historical roots of probability are found in gambling. One way to bridge the gap between school mathematics and students' lives is to address issues within society that directly impact the students' lives. For example, in Fiji a good example is the study of Fiji Sixes. This game is played all over the country, mostly by adults. The students could exchange information of the game, in particular, the popular beliefs about the game (luck, lucky numbers). The next step could be modelling the odds and the final step interpretation of results. These processes and whole class discussions might lead to students re-considering their own ideas and other social issues.

Teachers need to be sensitive to the possible effects of cultural differences, in particular as seen through religion as discussed earlier. Teachers may need to point out to students that there are alternative points of view. Students learn that questioning religion in any form is completely inappropriate and seen as a challenging. A number of students in the study drew upon their religious beliefs when resolving their thinking. Indian cultural influences such as God decides the sex of the baby need to be addressed during the teaching and learning process to ensure that students construct other appropriate views of probability and that will promote and enhance their statistical thinking. For example, if students come to the class with the religious view that God decides the sex of a baby and the teacher is trying to teach the mathematical view that chance is blind and not controlled by prior knowledge, then how this can be done in a way that does not denigrate the first view needs to be investigated. It is important to point out to students that there are alternative points of view. This could be achieved by taking a socio-cultural view of learning which recognises the importance of both the individual and communal activities.

This paper into identifying and describing students' reasoning in regards to probability constructs has opened up possibilities to do further research at a macro-level on students' thinking and to develop more explicit descriptors for each stage of the rubric (Table 1) used in this study. Much more understanding about students' thinking can be obtained when tasks allow for demonstration of several levels of student thinking. Such research would validate the categories of response types described in the current rubric and raise more awareness of the levels of thinking that need to be considered when planning instruction and developing students' probabilistic thinking. It is suggested that another category could be included in the current rubric which allows for the integration of both cultural and domain knowledge. Ainley and Pratt (2010) have shown how this can be done with respect to interpreting media graphs.

The use of open-ended tasks gave students the opportunity to display their understandings in both school and everyday contexts. However, some gaps in the content covered with respect to topics in the curriculum and literature emerged when the overall findings were considered. For example, there were no items that explicitly investigated more complex notions such as variation and randomness. There were also issues with the wording and format of tasks. Students certainly had difficulty interpreting the proportional reasoning task. Questions need to be structured to allow for varying degrees of difficulty. Some may build up interest through an extended series of questions as Item 2 whereas others are shorter but striking in their context as in task 1. Such issues could be addressed in future research.

The participants in Sharma study were a fairly small non-random sample from one school. Thus, the findings, in particular the number of students who thought about probability in a particular way may or may not generalize to the population of secondary school students as a whole in Fiji. There is a need for more research with larger, more random samples with different backgrounds to determine how common these ways of thinking are in the general population.

Furthermore, as mentioned earlier, the results reported in this paper were part of a larger study which focused on a number of areas of statistics. Since there had been virtually no research focused on probability outside western countries, it was not clear when this study was conducted that the questions discussed in this paper would be as rich and interesting as they were. Now that the cultural aspects described in this paper have been identified as possible areas of concern, there is a need for more qualitative research focused on a deeper understanding of students' thinking about probability concepts.

Cognitive, affective, and contextual aspects are interrelated during the interpretation of probability tasks. As mentioned earlier, Sharma study focused on students' thinking about probability before they had studied probability as a part of their senior secondary course work. There is a need for research that examines students' thinking about these concepts after they have completed their senior secondary coursework. In particular, there is a need to examine the effects of different types of instruction on students' thinking in these areas. This will help clarify cultural issues as well as ambiguous effects of teaching. 
In Sharma study, while some pupils answered some questions with reference to the numerical values, others used their cultural knowledge on other items. It would be interesting to see how easily (or whether) students who argued on the basis of cultural knowledge on these questions could be persuaded to argue purely on the basis of the numerical data. Pratt (2005, p. 185) argues that if "children have seen the lack of explanatory power of their own ideas they would reconsider recently learned knowledge." Future research could incorporate this into the interview procedure to explore this issue in more depth across different contexts.

The most critical person in any learning environment is the teacher. A number of researchers have highlighted the importance of teachers' own knowledge of probability (Jones et al., 2007; Stohl, 2005). With respect to culture, Greer and Mukhopadhyay (2005) caution us that probability has been introduced with minimal regard to historical and cultural contexts in spite of the fact that it is a cultural construction historically linked to religious issues. Teacher educators need to be aware of not only of students' probability knowledge but how the understanding of their cultural knowledge is likely to develop. Research efforts at this level are required. Through cultural studies we may gain some perspective on the forces and issues that have contributed to change in statistics education and suggest ways to be considered as we ponder their solutions.

\section{Concluding Thoughts}

Probability must be understood as a kind of cultural knowledge which all cultures create but which may not necessarily look the same from one cultural setting to another. With the large numbers of ethnic groups in mainstream classrooms all over the world with blanket probability programs, it is important to actually listen to student voices to understand what or what may not work for these students in terms of their probabilistic thinking. It is hoped that the findings reported in this paper will generate more interest in research with respect to cultural ideas that students possess and cultural differences that may impact on student learning. Teachers, curriculum developers and researchers need to work together to find better ways to help all students develop probabilistic thinking.

\section{References}

Abbas, T. (2002). Teacher Perceptions of South Asians in Birmingham Schools and Colleges. Oxford Review of Education, 28(4), 447-471.

Ainley, J., \& Pratt, D. (2010). It's not what you know, it's recognising the power of what you know: assessing understanding of utility. In C. Reading (Ed.), Proceedings of the 8th International Conference on the Teaching of Statistics, Ljubljana, Solvenia: International Statistical Institute and International Association for Statistical Education. Retrieved from http://www.Stat.Auckland.Ac.Nz/ Iase/Publications

Amir, G., \& Williams, J. (1999). Cultural Influences on Children's Probabilistic Thinking. Journal of Mathematical Behavior, 18(10), 85-107. http://dx.doi.org/10.1016/S0732-3123(99)00018-8

Ascher, M. (1991). Ethnomathematics: A multicultural view of mathematical ideas. Pacific Grove, USA: Brooks/ Cole Publishing Company.

Averill, R., Anderson, D., Easton, H., Te Maro, P., Smith, D., \& Hynds, A. (2009). Culturally response teaching of mathematics: Three models from linked studies. Journal for Research in Mathematics Education, 40(2), 157-186.

Barker, M. (2001). How do people learn? Understanding the process. In C. McGee \& D. Fraser (Eds.), The professional practice of teaching. Palmerston North: Dunmore Press.

Batanero, C., Henry, M., \& Parzysz, B. (2005). The nature of chance and probability. In G. A. Jones (Ed.), Exploring probability in school: Challenges for teaching and learning (pp. 15-37). New York: Springer.

Benn, R., \& Burton, R. (1996). Mathematics: A peek into the mind of God? Philosophy of Mathematics Education Newsletter, 9, 5-9.

Best, J. (2001). Damned Lies and Statistics: Untangling Numbers from the media, politicians and activist. Berkeley: University of California Press.

Bishop, A. J. (1994). Cultural conflicts in mathematics education. Developing a research agenda. For the learning of mathematics, $14(2), 15-18$.

Bishop, A. (1988). Mathematical enculturation: A cultural perspective on mathematics education. Dordrecht, Germany: Kluwer. 
Bourdieu, P. (1984). Distinction: A social critique of the judgement of taste. Cambridge, MA: Harvard University Press.

Canada, D. L. (2006). Elementary pre-service teachers' conceptions of variation in a probability context. Statistics Education Research Journal, 5(1), 36-63.

Chiesi, F., \& Primi, C. (2009). Recency effects in primary-age children and college students. International Electronic Journal of Mathematics Education, 4(3), 259-274.

Clark, M. (2001). Cross-cultural issues with students from the South Pacific Australian Mathematics Teacher, 57(1), 17-20.

Cobb, P. (1994). Where is the mind? Constructivist and sociocultural perspectives on mathematical development. Educational Researcher, 23(7), 13-20.

Confrey, J., \& Kazak, S. (2006). A thirty-year reflection on constructivism in mathematics education in PME. In A. Gutiérrez \& P. Boero (Eds.), Handbook of Research on the Psychology of Mathematics Education: Past, Present and Future (pp.305-345). Rotterdam: Sense Publishers.

D'Ambrosio, U. (2001). What is ethnomathematics, and how can it help children in schools? Teaching Children Mathematics, 7(6), 308.

De Abreu, G., Bishop, A. J., \& Pompeu, G. (1992). Approaches to research into cultural conflicts in mathematics learning. In Proceedings of the $16^{\text {th }}$ PME conference, University of New Hampshire, Durham.

Dickenson-Jones, A. (2008). Transforming Ethnomathematical Ideas in Western Mathematics Curriculum Texts. Mathematics Education Research Journal, 20(3), 32-53. http://dx.doi.org/10.1007/BF03217529

Fijian Ministry of Education, Women, Culture, Science and Technology. (1994). Primary Mathematics Prescriptions. Suva: Curriculum Development Unit.

Fischbein, E., Nello, M. S., \& Marino, M. S. (1991). Factors affecting probabilistic judgements in children and adolescents. Educational Studies in Mathematics, 22, 523-549. http://dx.doi.org/10.1007/BF00312714

Fischbein, E., \& Schnarch, D. (1997). The evolution with age of probabilistic, intuitively based misconceptions. Journal for Research in Mathematics Education, 28, 96-105. http://dx.doi.org/10.2307/749665

Franklin, C., Kader, G., Mewborn, D., Moreno, J., Peck, R., Perry, M., \& Schaeffer, R.(2007). Guidelines for assessment and instruction in statistics education (GAISE) Report: A pre-K-12 curriculum framework. Alexandria, VA: American Statistical Association. Retrieved from http://www.amstat.org/education/gaise/GAISEPreK-12

Gabriel, K. (1996). Gambler way: Indian gaming in mythology, history, and archaeology in North America. Boulder, CO: Johnson Books.

Gal, I. (2005). Towards "Probability Literacy" for all citizens: Building blocks and instructional dilemmas. In G. A. Jones (Ed.), Exploring probability in school: Challenges for teaching and learning (pp.39-63). New York: Springer.

Gal, I. (2002). Adults' statistical literacy: Meanings, components, responsibilities. International Statistical Review, 70(1), 1-24.

Garfield, J. B., \& Gal, I. (1999). Teaching and assessing statistical reasoning. In L. V. Stiff. \& F. R. Curcio (Eds.), Developing Mathematical Reasoning in Grades K-12 (pp. 207-219). Reston, Virginia, National Council of Teachers of Mathematics.

Gigerenzer, G., \& Edwards, A. (2003). Simple tools for understanding risks: From innumeracy to insight. British Medical Journal, 327(7417), 741-744. http://dx.doi.org/10.1136/bmj.327.7417.741

Green, D. R. (1983). School pupil's probability concepts. Teaching Statistics, 5(2), 34-42. http://dx.doi.org/10.1111/j.1467-9639.1983.tb00493.x

Green, D. R. (1991). A longitudinal study of pupils' probability concepts. In D. Vere-Jones (ed.), Proceedings of the Third International Conference on Teaching Statistics, 1, 320-328. Voorburg, The Netherlands: International Statistical Institute.

Greer, B. (2001). Understanding probabilistic thinking: The legacy of Efraim Fischbein. Educational Studies in 
Mathematics, 45, 15-53. http://dx.doi.org/10.1023/A:1013801623755

Greer, G., \& Mukhopadhyay, S. (2005). Teaching and learning the mathematization of uncertainty: Historical, cultural, social and political contexts. In G. A. Jones (Ed.), Exploring probability in school: Challenges for teaching and learning (pp. 297-324). New York: Springer.

Groth, R. E. (2007). Reflections on a research-inspired lesson about the fairness of dice. Mathematics Teaching in the Middle school, 13(4), 237-243.

Gutstein, E., \& Peterson, B. (2005). Rethinking mathematics: Teaching social justice by the numbers. Milwaukee, WI: Rethinking Schools.

Haycock, K. (2001). Helping all students achieve: Closing the achievement gap. Educational Leadership, 58(6), 6-11.

Hill, H. C., Sleep, L., Lewis, J., \& Ball, D. (2007). Assessing teachers' mathematics knowledge:What knowledge matters and what evidence counts? In F. Lester (Ed.), Second handbook of research on mathematics teaching and learning (pp. 111-156). Reston, VA: National Council of Teachers of Mathematics.

Jones, G. A., Langrall, C. W., Thornton, C. A., \& Mogill, A. T. (1999). Students' probabilistic thinking in instruction. Journal for Research in Mathematics Education, 30, 487-519. http://dx.doi.org/10.2307/749771

Jones, G. A., Langrall, C. W., \& Mooney, E. S. (2007). Research in probability: Responding to classroom realities. In F. K. Lester Jr. (Ed.), Second Handbook of Research on Mathematics Teaching and Learning (pp. 909-955). Reston: The National Council of Teachers of Mathematics.

Kahneman, D., Slovic, P., \& Tversky, A. (1982). Judgment under uncertainty: Heuristics and biases. Cambridge, UK: Cambridge University Press.

Kapadia, R. (2009). Chance encounters - 20 years later fundamental ideas in teaching probability at school level. International Electronic Journal of Mathematics Education, 4(3), 371-386.

Konold, C. (1991). Understanding students' beliefs about probability. In E. von Glasersfeld (Ed.), Constructivism in mathematics education (pp. 139-156). Dordrecht, The Netherlands: Kluwer.

Lave, J., Murtaugh, M., \& de la Rocha, O. (1984). The dialectic of grocery shopping. In B. Rogoff \& J. Lave (Eds.), Everyday cognition: Its development in social context (pp. 67-94). Cambridge, MA: Harvard University Press.

Lave, J., \& Wenger, E. (1991). Situated learning and legitimate peripheral participation. Cambridge, UK: Cambridge University Press. http://dx.doi.org/10.1017/CBO9780511815355

Lubienski, S. (2002). Research, reform, and equity in US mathematics education. Mathematical Thinking and Learning, 4(2/3), 103-125. http://dx.doi.org/10.1207/S15327833MTL04023_2

Lecoutre, M. (1992). Cognitive models and problem spaces in purely random situations. Educational Studies in Mathematics, 23, 557-568. http://dx.doi.org/10.1007/BF00540060

Ma, L. (1999). Knowing and teaching elementary mathematics. Mahwah, NJ: Lawrence Erlbaum.

Martin, D. (2006). Mathematics learning and participation as racialized forms of experience: African American parents speak on the struggle for mathematics literacy. Mathematical Thinking and Learning, 8, 197-229. http://dx.doi.org/10.1207/s15327833mt10803_2

Ministry of Education. (2007). The New Zealand Curriculum. Wellington: Learning Media.

Moore, D. (1997). New pedagogy and new content: the case of statistics. International Statistical Review, 65(2), 123-165.

Nasir, N. S. (2000). Points ain't everything: Emergent goals and average and percent understanding in the play of basketball among African American students. Anthropology and Education Quarterly, 31, 283-305. http://dx.doi.org/10.1525/aeq.2000.31.3.283

Nasir, N. S. (2002). Identity, goals, and learning: Mathematics in cultural practice. Mathematical Thinking and Learning, 4(2/3), 213-248. http://dx.doi.org/10.1207/S15327833MTL04023_6

Nasir, N. S., Hand, V. \& Taylor, E. V. (2008). Culture and mathematics: Boundaries between "Cultural" and 
"Domain" knowledge in the mathematics classroom and beyond. Review of Research in Education, 32, $187-$ 240. http://dx.doi.org/10.3102/0091732X07308962

Nasir, N. S., \& Hand, V. (2006). Exploring sociocultural perspectives on race, culture, and learning. Review of Educational Research, 76(4), 449-475. http://dx.doi.org/10.3102/00346543076004449

Nunes, T., Schliemann, A., \& Carraher, D. (1993). Street mathematics and school mathematics. Cambridge, UK: Cambridge University Press.

Nickson, M. (1992). The culture of the mathematics classroom: An unknown quantity? In D. A. Grouws (Ed.) Handbook of research on mathematics teaching and learning (pp. 101-114). New York: Macmillan.

Peard, R. (1995). The effect of social background on the development of probabilistic reasoning. In A. J. Bishop (Ed.), Regional collaboration in mathematics education (pp. 561-570). Melbourne, VIC, Australia: Monash University.

Polaki, M. V. (2002). Using Instruction to Identify Key Features of Basotho Elementary Students' Growth in Probabilistic Thinking. Mathematical Thinking and Learning, 4, 285-314. http://dx.doi.org/10.1207/S15327833MTL0404_01

Pratt, D. (2005). How do teachers foster students' understanding of probability? In G. A. Jones (Ed.), Exploring probability in school: Challenges for teaching and learning (pp.171-189). New York: Springer.

Presmeg, N. (2007). The role of culture in teaching and learning mathematics. In F. K. Lester Jr (Ed.), Second Handbook of Research on Mathematics Teaching and Learning (pp. 435-458). Reston: The National Council of Teachers of Mathematics.

Noll, J. (2011). Graduate Teaching Assistants' Statistical Content Knowledge of Sampling. Statistics Education Research Journal, 10(2), 27-47.

Rossman, A., Chance, B., \& Medina, E. (2006). Some important comparisons between statistics and mathematics, and why teachers should care. In G. Burrill \& P. C. Elliot (Eds.), Thinking and reasoning with data and chance (pp. 323-333). Reston: The National Council of Teachers of Mathematics.

Scheaffer, R. L. (2006). Statistics and mathematics: On making a happy marriage. In G. Burrill \& P. C. Elliot (Eds.), Thinking and reasoning with data and chance (pp. 309-322). Reston: The National Council of Teachers of Mathematics.

Schield, M. (2010). Assessing Statistical Literacy: Take CARE. In P. Bidgood, N. Hunt \& F. Jolliffe (Eds), Assessment Methods in Statistical Education: An International Perspective (Chapter 11, pp. 133-152). John Wiley \& Sons Ltd. http://dx.doi.org/10.1002/9780470710470.ch11

Sharma, S. (1997). Statistical ideas of high school students: Some findings from Fiji. Unpublished doctoral thesis. Waikato University, Hamilton, New Zealand.

Shaughnessy, J. M. (1992). Research in probability and statistics: Reflections and directions. In D. Grouws (Ed.) Handbook of research on mathematics teaching and learning (pp. 465-494). New York: Macmillan.

Shaughnessy, J. M. (2007). Research on statistics learning and reasoning. In F. K. Lester(, Jr Ed.), Second Handbook of Research on Mathematics Teaching and Learning (pp. 957-1009). Reston: The National Council of Teachers of Mathematics.

Shaughnessy, J. M., \& Ciancetta, M. (2002). Students understanding of variability in a probability environment, Proceedings of the Sixth International Conference on Teaching Statistics.

Skovsmose, O. (1994). Towards a Philosophy of Critical Mathematics Education. Kluwer Academic Publishers, Dordrecht.

Stohl, H. (2005). Probability in teacher education and development. In G. A. Jones (Ed.), Exploring probability in school: Challenges for teaching and learning (pp. 297-324). New York: Springer.

Tate, W. F. (1997). Race-ethnicity, SES, gender, and language proficiency trends in mathematics achievement: An update. Journal for Research in Mathematics Education, 28(6), 652-679. http://dx.doi.org/10.2307/749636

Tarr, J. (2002). Providing opportunities to learn probability concepts. Teaching Children Mathematics, 8(8), 482487 . 
Truran, K. M. (1994). Children's understandings of random generators. In C. Beesey \& D. Rasmussen (Eds.), Mathematics Without Limits, Proceedings of the 31st Annual Conference of the Mathematical Association of Victoria, Melbourne (pp. 356-362). Mathematics Association of Victoria.

Vithal, R., \& Skovsmose, O. (1997). The End of Innocence: A Critique of "Ethnomathematics." Educational Studies in Mathematics, 34(2), 131-157. http://dx.doi.org/10.1023/A:1002971922833

Von Glasersfeld, E. (1993). Questions and answers about radical constructivism. In K. Tobin (Ed.), The practice of constructivism in science education (pp. 24-38). Washington: American Association for the Advancement of Science.

Vygotsky, L. (1978). Mind in society: The development of higher psychological processes. Cambridge: Harvard University Press.

Watson, J. M. (2006). Statistical literacy at school: Growth and goals. Mahwah, NJ: Lawrence Erlbaum.

Watson, J. M., \& Callingham, R. (2003). Statistical literacy: A complex hierarchical construct. Statistics Education Research Journal, 2(2), 3-46.

Wax, M. L. (1993). How culture misdirects multiculturalism. Anthropology \& Education Quarterly, 24(2), 99-115. http://dx.doi.org/10.1525/aeq.1993.24.2.05x1116x

Zaslavsky, C. (1998). Ethnomathematics and multicultural mathematics education. Teaching Children Mathematics, 4(9), 502-503.

Zimmermann, G. M., \& Jones, G. A. (2002). Probability simulation: What meaning does it have for high school students? Canadian Journal of Science, Mathematics and Technology Education, 2(2), 221-236. http://dx.doi.org/10.1080/14926150209556515 